\title{
Miang Culture: The Community Resources Management Through "Design-Based Learning” for Self-Reliance of Highland Communities in the Upper Northern Thailand
}

\author{
Grit Piriyatachagul ${ }^{1}$, Thongchai Phuwanatwichit ${ }^{2}$, Charin Mangkhang ${ }^{1} \&$ Atchara Sarobol $^{2}$ \\ ${ }^{1}$ Faculty of Education, Chiang Mai University, Thailand \\ ${ }^{2}$ Faculty of Humanities, Chiang Mai University, Thailand \\ Correspondence: Grit Piriyatachagul, Faculty of Education, Chiang Mai University, 239 Huay Kaew Rd, Suthep, \\ Mueang District, Chiang Mai, 50200, Thailand. Tel: 66-624-149-090. E-mail: piriyatachagul.g@gmail.com
}

\author{
Received: May 31, $2020 \quad$ Accepted: July 5, $2020 \quad$ Online Published: July 12, 2020 \\ doi:10.5539/hes.v10n3p63 URL: https://doi.org/10.5539/hes.v10n3p63
}

\begin{abstract}
The purpose of this article is to describe the formation of Miang resource management of the highland communities in the Upper Northern Thailand through design-based learning which is the mechanism to learning the management of the communities' resource for self-reliance derived from the solid and strong foundation of the communities. The method utilized in the quality research, collecting the information from the documentary study, participatory and non-participatory observation, and the deep interview with the community philosopher, and the data is analyzed by using the content analysis method. The research found that most of the highland communities in the Upper Northern Thailand located at the west of Phi Pan Nam Mountains have a lifestyle that connects with the participatory Miang resource management, have wisdom which is the innovation of design-based learning for self-reliance of the communities through the accumulating and the transfer of the knowledge from generation to a generation called "Miang Culture" which is created from the systematic design-based learning process through the wisely utilization of Miang resource existing in the community, and to cause the maximum sustainability based on the participation of the community without causing the trouble or breaching other's right.
\end{abstract}

Keywords: Miang culture, design-based learning, community resources management

\section{Introduction}

At this moment, the importance of the management of community resources is increased because the human lifestyle must utilize the various kind of natural resources existing in the community either the forest resource, soil, water, or biodiversity. It is found that the need increases by the growth of economics, society, science, technology, and the expansion of the population. If there is no the appropriate resource management, there may be the problem of usurpation of resource, degradation of natural resource and the environment problem, and the communities may be unable to exist (Phuwanatwichit, 2017).

Thus, the participation of all sectors in society to manage resources together is one of the ideas to empower the community to participate in the management of community resources to cause the appropriate utilization, maintenance, reparation, and recovery of the utilization of resources. Such process leads to the way to improve the community and cause the sustainable self-reliance, especially the lifestyle and the living, because the providing to the community the right to freely choose its future will cause the community to find and use its potential (Prokkati, 2007), at the same time, it is also the proof to society that local community can serve the society, at least, with the take care of nation's resource. Thus, community resource management has the relation with the utilization of existing resources in the community to cause value which conforms with the community's lifestyle, and context based on the participation (Puangngam, 2008) without causing trouble and the breaching of other's right.

"Miang" is a vernacular plant which is mostly found and able to grow in the highland communities in the Upper Northern Thailand, it is a perennial plant in the Assam family (Camellia sinensis var. assamica) having relation with Lanna's lifestyle because most of the community in the Upper Northern Thailand have lifestyle relating to nature, the wisdom of making of Miang and the forest management system recognizing the environment problem, 
self-reliance in community and the relationship management between human and human, between human and nature and between human and supernatural (Pinprateep, 2008). All of these are fused to become the living together with the lifestyle of the people in the Miang community and the value of Miang culture through the accumulating and the transfer of knowledge from generation to generation. While the current young people may not know the word "Miang" and the eating of Miang, but they know it in the form of "tea" and give the value of "tea" instead.

So, the study of Miang resource management of highland communities in the Upper Northern Thailand through design-based learning will lead to the knowledge of the form of the management of community resource for self-reliance, the sustainable living and the solving problem in community level through the using of knowledge, skill, belief, and behavior derived from all activities of people in society that design, learn and adapt to survive together (Wongsasunt, 1999) and to deeply understand the problem centered on the community who gain the interest and maintenance until the creation of wisdom which is the Innovation of design thinking for all that meet the community's context (DEX Space, 2016) and the benefit of humanity.

\section{Conceptual Framework}

The concept of community resources management through "Design-Based Learning"

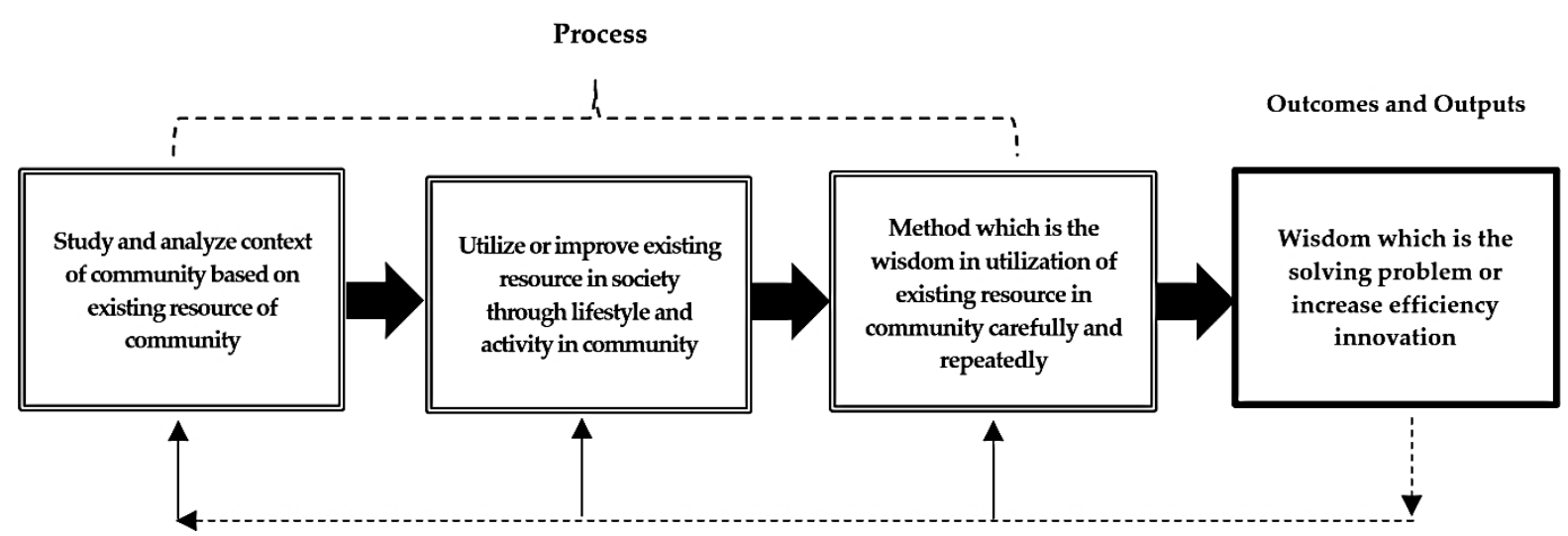

Figure 1. The Framework of the concept of community resources management through "Design-Based Learning"

(Source: adjusted from Amiel \& Reeves, 2008)

Community resource is important to the living of the community because people in the community take advantage of the resource for the survival of the lifestyle. Aside from taking advantage, the community must also protect the resource from being destroyed together. So, community resource management is the learning of the people in the community, the exchange of knowledge and transfer of experience to create the agreement, rule, and conduct together, either in economics, society and culture, or natural resource and environment (Phuwanatwichit, 2015). Community resource management is also the wisdom of having a dynamic learning process through education until the creation of wisdom and crystalizes into knowledge thoroughly and carefully created having a duty to direct how to live sustainably and permanently with nature.

The study of community resource management through design-based learning is the process to show that community studies, designs, and learns at the same time, based on theory and the action. Moreover, it also the characteristic of the participatory action learning causing the model of the learning which is the wisdom or innovation suitable to the context of the community and create the highest development of the community. It is found that the important characteristics of community resource management through design-based learning are as follows: 
Table 1. Important Characteristics of Community Resource Management through "Design-Based Learning"

\begin{tabular}{ll}
\hline Design-Based Learning & Important Characteristic \\
\hline Community Context & $\begin{array}{l}\text { Created from the situation or phenomenon in real life, most of them } \\
\text { create the learning to solve the problem and adapt for the survival of the } \\
\text { villagers and the community } \\
\text { 1. Dependent variable such as the cooperation in the community, } \\
\text { existing resource } \\
\text { 2. Output variable such as the learning, transferring process } \\
\text { 3. System variable such as sustainability, self-reliance }\end{array}$ \\
Focus of Learning & $\begin{array}{l}\text { Focus on complex characteristics of situation or phenomenon } \\
\text { Designed to be flexible without causing trouble or breaching of other's } \\
\text { right }\end{array}$ \\
Amothod & $\begin{array}{l}\text { The complex intervention of community by sharing of idea } \\
\text { Seeing the design in various aspect and having characteristic as practical } \\
\text { design }\end{array}$ \\
Characteristic of Learning Result & Community participation to create and analysis design \\
\hline
\end{tabular}

(Source: adjusted from Collins, 1999)

The researcher has a synthesized form of development of community resource management through the design-based learning process as having 5 steps as follows:

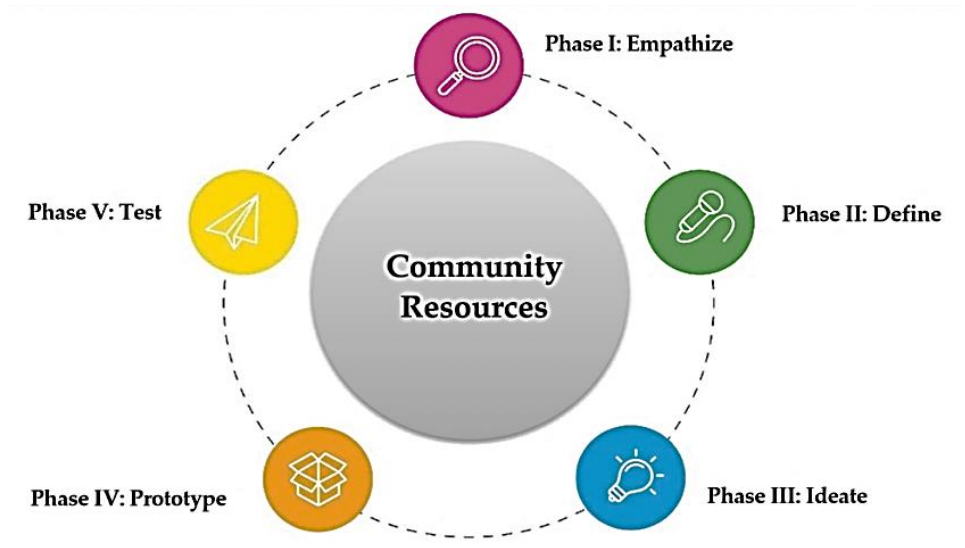

Figure 2. Form of community resource management through the design-based learning process

(Source: adjusted from Brunetto S. K., 2018)

$1^{\text {st }}$ Step Understanding the context of area (Empathize) is the study and understanding of the condition and geography of the community.

$2^{\text {nd }}$ Step Defining the need (Define) is the understanding of the problem using the method of analyst and holistic thinking system.

$3^{\text {rd }}$ Step Solution to solve the problem (Ideate) is the brainstorming of new ideas using the method of the innovation creator based on the existing resource of the community.

$4^{\text {th }}$ Step Creation of innovation (Prototype) is the research, trial and error learning and repetition until the creation of the process or knowledge which is its wisdom.

$5^{\text {th }}$ Step Testing (Test) is the use of innovation with flexibility and hope for practical results to improve the quality of life and the living of the people in the community to sustainably self-reliance and able to transfer endlessly and dynamically.

It is found that the most important part of community resource management starts from understanding the context of the area which leads to the study and improve the process of such wisdom (Context to Content). The learning process must be designed through the base of existing resources in the community which is useful to the improvement of the community in many dimensions, to improve the quality of life, and to create the feeling of participation and sense of ownership. 
Thus, design-based learning is one of the learning processes of the community that is not developed or created through formal education but through informal education which is adapted to "the design of living" that the community is unaware of. The charm and usefulness of such learning process are that it causes many people who are the stakeholder of the existing community resource to solve the problem together which create "Collaborative Innovation" that meet the problem following the existing limitation.

Community resource management through design-based learning in the form of learning to mix between concept and process of the design which, under the principle of design-based learning, is considered as the development of advanced ability to think. As a result, the community resource management is the wisdom of the community through the design-based learning having advance systemic thinking to solve the problem, adapt and learn for the survival of the people in the community, and the tactic to solve a complex practical problem and relate to the community context.

\section{Method}

\subsection{Scope of the Study}

\subsubsection{Scope of Area}

The area of this study is Baan Mae Thon Luang Community, Thep Sadej Subdistrict, Doi Saket District, Chiang Mai Province.

\subsubsection{Scope of Content}

The contents of this study consist of community context, a form of Miang resources management for self-reliance of Baan Mae Thon Luang Community, Thep Sadej Subdistrict, Doi Saket District, Chiang Mai Province. The issues of the study are, for example, lifestyle, conditions of living, culture, and tradition, the relation between community, Miang culture, and Miang resources management for self-reliance of community.

\subsubsection{Scope of Population and Sample Group}

The population of this study is the philosopher of the community of Baan Mae Thon Luang Community, Thep Sadej Subdistrict, Doi Saket District, Chiang Mai Province. The researcher chooses sample groups by purposive sampling and accidental sampling to gain information from not less than 20 persons of sample group including an unable specified amount of person having knowledge who can provide information during the field study.

\subsection{Methodology of the study}

\subsubsection{Method of Study}

This study is the qualitative research to find the knowledge that is the wisdom of community which must be made by refinement, precision, profundity, and continuity in the study to get the fact reflecting various aspect to be used for the analysis of the form of community resource management through design-based learning for self-reliance of community.

\subsubsection{Method of Collecting Data}

1) A documentary study by collect data from documents, books, journals either relating theory, concept, or research focusing on the information other than an interview or then put them together.

2) A field study by using participatory and non-participatory observation including the deep interview with community philosopher

Provided that, the researcher will test the completion, correctness and the precision of the information (Validity) and assess the accuracy and reliability of the research by 1) test by using Triangulation Technique 2) check with the information provider and 3) check the information received from the interview with the relating research.

\subsubsection{Tools Utilized in the Study}

1) Structured Interview by using in-depth interviews in which the researcher has set the structure of question in advance before the interview of a specified sample group to get the most truthful answer from the sample group.

2) Field Study Record for the participatory and non-participatory observation to record details while making the field collection of information and use the information together with the information analysis and describe the phenomenon.

Provided that, the tools used in the study is tested the validity and reliability with the experienced expert.

\subsubsection{Analysis of Information}

In this study, the researcher uses content analysis and thematic analysis to analyze the relationship of the 
information together with the concept of design-based learning, prioritize the importance of information and present the research result in form of hermeneutic description.

\subsubsection{Ethical Consideration}

To observe the highly confidential nature of the study and the interviews, no particular names were mentioned in the study. The identity of the respondents was undisclosed. No personal opinions were given by the researchers, only information and results based on the data to be gathered. The research participants should not be subjected to harm in any way the results or findings of the study. The study considered high respect for the dignity of research to be prioritized and full consent should be obtained from the participant before the study.

\section{Results}

The results are presented in 2 dimensions as follows;

4.1 Local Context: Cultural Ecology System of Baan Mae Thon Luang Community, Thep Sadej Subdistrict, Doi Saket District, Chiang Mai Province

Baan Mae Thon Luang Community, Thep Sadej Subdistrict, Doi Saket District, Chiang Mai Province is the location of Pa Miang community located on the west of Phi Pan Nam Mountains which is the important upstream resource for the consumption in flat land in the Upper Northern of Thailand. The area of the community is the $1 \mathrm{~A}$ class watershed forest. The lifestyle of the community connects with the Miang resource and has the wisdom to cultivate in the form of Pa Miang mixing with the montane forest.

Miang is not just a vernacular plant in community agriculture. The community has wisdom in planting mixing Miang in form of agroforestry without the need for an irrigation system to make food and keep the balance of the environment than the production of goods. The villagers living in the community have to protect the forest by using it.

Pa Miang as the buffer zone to protect the montane forest. There is the prevention of wildfire by making firebreak together every year before the drying season to prevent the spread of fire to their and community's Pa Miang. Importantly, in this kind of agriculture, the villagers will strictly not use the fertilizer or pesticide in Pa Miang which causes the water in the stream flowing into flatland can clean itself and become pure water without toxic.

Pa Miang cultural ecology system is the local wisdom to manage the agroforestry system through learning, accumulating, and transferring knowledge from generation to generation for a long time. The villagers in the community will help taking care of Miang grown sporadically in this ecology system to make Pa Miang exist alongside the forest in the valley and plain ecology system for a long time. As Pa Miang ecology system is the area that can keep the biodiversity having the complex agriculture that has may level of the mixed plant, and Miang is the medium-low shrub growing among tall canopy while the forest floor has small plant all round, so Pa Miang cultural ecology system has the role to keep the stability of watershed forest (Ganjanapan et al., 2017).

While, at this moment, Pa Miang cultural ecology system in highland in the Upper Northern of Thailand is challenged by the expansion of the relationship with outside society, Pa Miang cultural ecology system of Baan Mae Thon Luang Community still exists because such system connects with the complex community resource management mixing in Pa Miang. The community helps to monitor the invasion from an outside investor, has the community's rule, has the strength to manage the forest recognizing the environment problem, understands right, has learning and value, and is proud of Miang's career. If the community must lose any part of its identity and area context, it may lead to the destruction of all systems. So, villagers in Baan Mae Thon Luang community help to protect this ecology system as long as possible because it is local wisdom to keep sustainability and take advantage of Miang culture for self-reliance for a long time.

4.2 The Community Resources Management Through "Design-Based Learning” for self-reliance of Baan Mae Thon Luang Community, Thep Sadej Subdistrict, Doi Saket District, Chiang Mai Province

From the result of the study of the community resources management through design-based learning in Baan Mae Thon Luang Community, Thep Sadej Subdistrict, Doi Saket District, Chiang Mai Province, it is found that community has the wisdom of community resource management through participatory Miang culture, and Miang culture connects to the lifestyle of the people in the community, either in economics, society, and tradition, natural resource or environment which fuse into the lifestyle of self-reliance and living together of the community that has inherited wisdom from generation to generation, which can be divided into 3 areas as follows:

1) Society and Tradition from the study, the community has the learning through the design and creation of the 
product by steam and ferment Miang and eat it as the eating culture and the foundation of relationship in society. In the past, every house has Miang as a snack. The villager likes to keep Miang in the mount after the meal and use Miang to welcome visitor and visiting relatives.

Baan Mae Thon Luang community has the wisdom to make Miang by the learning through well-selected inheritance, development, improvement, and selection process that is the villager will harvest Miang by "Wai Huu" which is the harvest by picking up 3 quarters of a leaf, because the villagers have learned and believed that if all part of Miang is harvested, Miang will not grow new leaf and cause Miang dies. Then the harvested Miang leaves will be steamed, let cool, tied in a bamboo basket, and fermented in water. If they want acerbity Miang, the period of ferment will be approximately 14 days, but if they want soar Miang, the period of ferment will be not less than 2 months and Miang will have good taste, beautiful and natural color and is appetizing which is called "Miang Som".

Moreover, it is found that Miang also has a role in making merit tradition in Buddhism. The community uses Miang as offering in rite such as housewarming, wedding, fortune-telling, offering robe, ordination, morale, kathin, and funeral, including the belief of villagers that is "Poo Ja Pee" or the treating ghost the meal.

At this moment, Miang may not be the favorite eating culture in the past. The number of people eating Miang reduces from time to time and such tradition is favorite only in the elderly and labor groups. Miang, however, does not completely disappear from the community. From the interview with the community philosopher in Baan Mae Thon Luang, Miang remains in the spirit of the people in the community because Miang context in Baan Mae Thon Luang community is still living according to the value of compound in Miang that is power booster, refreshing, anxiety relief, and snack during the rest time for labor group and villager. From the interview with community philosopher, it is confirmed that consumption of Miang effectively cures drowsiness and Miang is metaphorical as "Ole Doi" (Ole was the very popular candy for one period in Thailand) and Miang is still the eating culture of people in the community, the villagers use Miang to make the food such as Miang leaves salad, Nam Miang (water remaining from the steam of Miang which is simmered until thicken and flavored).

2) Economic when Miang is part of the eating culture of Lanna (The Upper Northern of Thailand), Miang becomes the goods having economic relations with the community. In the past, when people of Pa Miang need many laborers for production, Pa Miang became the important working place in the highland area which creates income for the flat land unemployed worker. And because of the limited area for rice growing in highland, people of Pa Miang must exchange Miang for rice with the people in flat land (LeBar, 1967). Thus, the relationship between people in Pa Miang in highland and people in flat land is dependent relationship and exchange of interest which is systemically designed and learned and being developed and exist for a long time.

When the need for consumption of Miang is increased and expanded to many villages throughout the North, Miang has an important role as a cash crop which creates a lot of income to the local market, inferior only to rice and teak (The Record, 1923). Pa Miang Community is increasingly dragged into currency economy network, from the past that use Miang to exchange for rice into use currency instead causing a new group of middlemen that drove Tang-Cow seller out and became the group having an important role to control Miang market called "Poe Liang Miang".

From the study, at this moment, all families in Baan Mae Thon Luang Community is making Pa Miang as the main career. Miang in the economic system of Baan Thon Luang Community comprises of 1) Miang harvester who is the most important labor in Miang system because the harvesting process must use skill and expertise, 2) Miang fermenter, who, mostly, the person having some capital in community and buy Miang from Miang harvester, and 3) Por Liang Miang who is the middleman distributing Miang to market and being the capital source of the selling of Miang. When the harvest season arrives, Por Liang Miang will reserve money for Miang harvester and Miang fermenter to borrow for the living cost in exchange for the promise that they shall repay by Miang in the value equal to borrowed money without written agreement but using confidence.

So, Miang resource management in economic dimension is one option of the survival way of community and is the welfare management of community-based on the community resource through the design and learning from the past to present, to create social security by focusing on self-reliance on the base of existing resource in the community either the social capital of tradition capital without the need to seek for help from the government. 


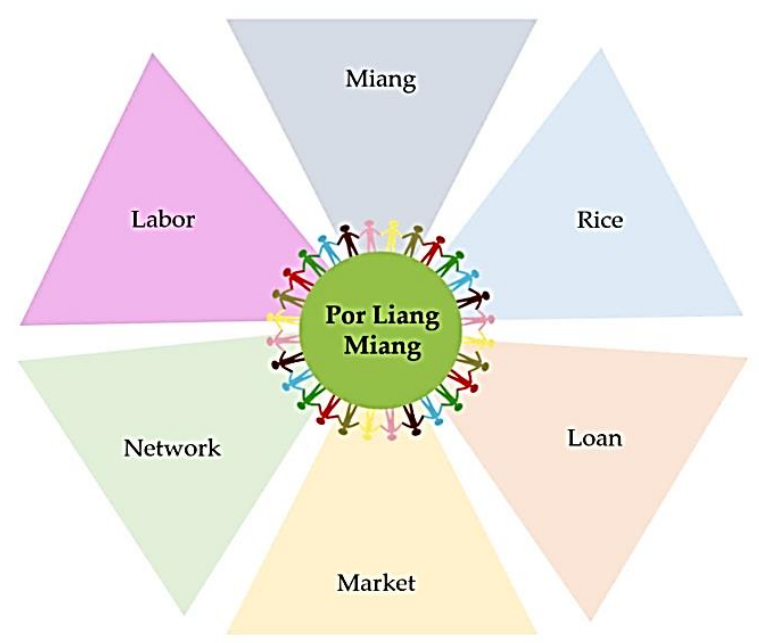

Figure 3. Role and relation of Por Liang Miang in the economic with Pa Miang community

\section{Natural Resource and Environment}

Miang culture is the wisdom on community resource management existing alongside the community in highland in the Upper Northern Thailand since in the past. It is the form of forest management as the forest area for the production and the common property of the community (Wichienkeeo, 2009). The characteristic of Pa Miang is "Common Forest" or forest of the community mixing of the community forest, conservation forest, and usual forest in the same area. Each villager will take care Miang tree as his/her property in the form of common property that is the sharing of resources and take advantage of together from Pa Miang in community.

From the study. Miang is the biological plant indicating the abundance and purity of the forest. As Miang is the plant that lives under the shade of large trees, grows on the wet forest floor and being the watershed forest class 1A, Miang is the cultural plant having an important role to conserve watershed forest and the forest of the highland community, and Miang also helps to protect from a disaster such as being the zone protecting from the forest fire, storm, floods, drought and ground salinity including preventing the shifting farming and the invasion to destroy the forest resulting from the changing of the area from natural capital to the capital created for the temporary economic benefit of a developing country. (Yeo et al., 2016)

Moreover, Pa Miang system also keeps the biodiversity not only tea strain but also many other plants and animals. Pa Miang has plant naturally grown consist of various large trees, shrub, and plant living on the other plant, ivy, parasitic, fern, and herbaceous plant. Thus, Pa Miang is the Agroecosystem which is the production system directly taking advantage of forest resources, both planting area and relating production, but not affect the forest because Miang living under the shade of the large tree, so there is no need to adjust the area a lot. The community uses a large amount of firewood to steam Miang, but it does not affect the forest.

From the study, Baan Mae Thon Luang community has knowledge that is the wisdom to manage the forest that is the villagers will not cut firewood in the rainy season because if they do so, the tree shall not have offshoot and such tree shall die but if the cutting tree for firewood is made in winter, from the December until March, the tree will have 4-6 offshoots. Most of the tree does not grow fast and must leave for 2-3 years. 2-3 offshoots of each clump shall be separated for the user and the remaining offshoots are allowed to grow and propagate naturally. With this process, the forest will not be exhausted and remain intact all the time. This process is considered as the dynamic use of firewood by a villager of Baan Mae Thon Luang community which is designed and transferred for a long time.

Pa Miang management of Baan Mae Thon Luang community also has the concept that humans must be able to live with the forest, so the career of making Miang is conducive to the keeping of forest which cannot be indicated that where is the workplace, the forest or the community area. At this moment, villagers increase the taking of advantage from Pa Miang by growing coffee together with Miang. The growing and taking care of coffee is the same as Miang that is it must be grown under the shade of large trees causing the coffee tree to flourish and give good results. Coffee trees and Miang trees can live together. Coffee of Baan Mae Thon Luang community has been registered as Geographical indication (GI) having its smell and taste derived from Pa Miang, Pung Gown, and Pa Mai Kor cultural ecology system. The abundance of 
water and the suitability of weather also affect the quality and identity of coffee grown among Pa Miang.

\section{Discussion and Conclusion}

Local wisdom is the knowledge created from accumulate experience through the learning process and inheritance designed to solve the problem and improve the living quality of the people in the community to be balanced with the environment and suitable to the era based on the existing resource in the community. It is the set of knowledge which can be made repeatedly to solve the problem and to adapt to the change of the relation between the local community and biodiversity reflecting the way of thinking in the management of the relationship between human and human, human and nature and human and supernatural which is conducive to the living.

Miang resource management through "Design-Based Learning" for self-reliance of highland communities in the Upper Northern Thailand is the power driving the development of economics, society, tradition, and natural resource and environment of the community. It applies local knowledge and wisdom in living in the community way conforming with the Theory of Situated learning which describes that the learning cannot freely be created from the context of society and tradition but created in "real situation" under the value and culture of such society. The learning is not only the modification of old knowledge to conform with the knowledge accepted in society, but also being the design and development of the ability to participate in the society of person having knowledge, and the community must learn to assess and manage the real situation in a complex social context which may be starting from the learning in a less complex situation to more complex situation (Cobb \& Bowers, 1999).

Community resource management through design-based learning is the process that completely supports the community to self-reliance or making the self-reliance citizen through the learning in the community including help new generation of the citizen to recognize the role and duty to take care the forest which is the important treasure source of the county without destroying themselves and community environment, to push forward Pa Miang cultural ecology system to steady exist, to keep the wisdom and to improve to the promotion of the community to live with value. However, from the study and analysis, the researcher has summarized the process of Miang resource management through "Design-Based Learning” for self-reliance of the community as follows:

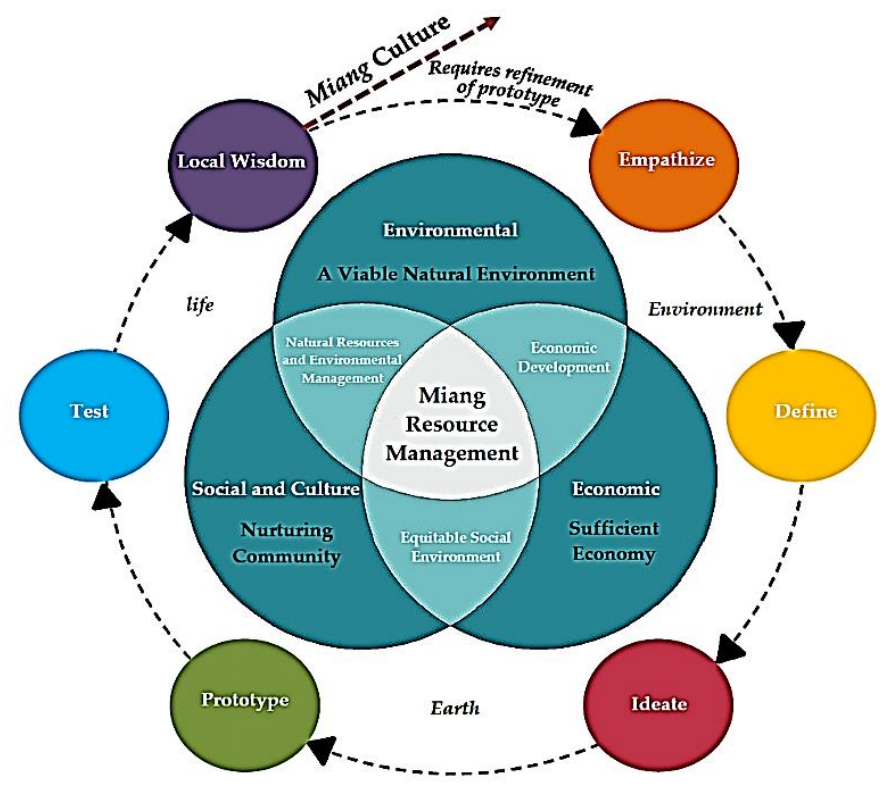

Figure 4. Process of Miang resource management through “Design-Based Learning” for self-reliance of Baan Mae Thon Luang Community, Thep Sadej Subdistrict, Doi Saket District, Chiang Mai Province

Thus, Miang resource management of Baan Mae Thon Luang Community, Chiang Mai Province is the example of the form of community resource management through design-based learning for self-reliance of highland communities in the Upper Northern Thailand created from the intelligence, learning, design and transferring of long experience of the people in community until becoming "Miang culture" which directs the design of community sustainable lifestyle of self-reliance. 


\section{References}

Amiel, T., \& Reeves, T. C. (2008). Design-Based Research and Educational Technology: Rethinking Technology and the Research Agenda. Educational Technology \& Society, 11(4), 29-40.

Brunetto, S. K. (2018). A glimpse on innovation: How do we structure the Design Thinking process at INNOVATION RADICALS. Retrieved from https://medium.com/@ sebastiankummetzbrunetto/a-glimpse-on-innovation-how-do-we-structure-the-design -thinking-process-at-innovation-radicals-6fcdf5583d74

Cobb, P., \& Bowers, J. (1999). Cognitive and Situated Learning Perspectives in Theory and Practice. Educational Researcher, 28(2), 4-15. https://doi.org/10.3102/0013189X028002004

Collins, A. (1999). The Changing Infrastructure of Education Research. In E. Lagemann \& L. Shulman (Eds.), Issues in Education Research. San Francisco: Jossey-Bass.

DEX Space. (2016). What is Design Thinking? (Overview). Retrieved from https://medium.com/base-the-business-playhouse/design-thinking- What is-overview-dc8c8e $7547 \mathrm{db}$

Ganjanapan, A., Charoenmuang, T., Trakarnsirinont, W., Kanongnuch, C., \& Sangchai, W. (2017). The Wisdom and Value of Miang in Lanna. Chiang Mai: Office of Research Administration, Chiang Mai University.

LeBar, F. M. (1967). Miang: Fermented Tea in North Thailand. Behavior Science Note, 2, 105-121. https://doi.org/10.1177/106939716700200206

Phuwanatwichit, T. (2015). Conceptual Framework of the Community Welfare Concept Based on Community Resources: Choices for Sustainable Community Self-Reliance. "MFU Connexion” Journal of Humanities and Social Sciences, 4(2), 65-94.

Phuwanatwichit, T. (2017). Sustainable community resources management. Chiang Mai: Faculty of Humanities, Chiang Mai University.

Pinprateep, P. (2008). Citizen participation in rural development projects of Thailand; volume commemorating the 20th anniversary of the Local Development Institute of Thailand. Bangkok: Local Development Foundation.

Prokkati, K. (2007). Right of people that come together as a community. Bangkok: Winyuchon Press.

Puangngam, K. (2008). Community and Local self Government. Bangkok: Bophit Printing.

The Record. (1923). Report on the Cultivation of Miang. The Record, 3(1), 16-20.

Wongsasan, K. (1999). Thai ways of life. Bangkok: Thiadwave Education.

Wichienkeeo, A. (2009). Forest Management in Northern Thailand: A Study from the Early 18th Century Palm leaf Text. The Journal of the Royal Institute of Thailand, I.

Yeo, L. B., Said, I., Saito, K., \& Ling, G. H. T. (2016). Conceptual Framework of Ecosystem Services in Landscape Planning, Malaysia. International Journal of Built Environment and Sustainability, 3(3), 142-149. https://doi.org/10.11113/ijbes.v3.n3.137

\section{Copyrights}

Copyright for this article is retained by the author(s), with first publication rights granted to the journal.

This is an open-access article distributed under the terms and conditions of the Creative Commons Attribution license (http://creativecommons.org/licenses/by/4.0/). 